\title{
ANALISIS FUNGSI LEGENDA TELAGA SARANGAN DI KELURAHAN SARANGAN KEC. PLAOSAN KAB. MAGETAN JAWA TIMUR
}

\author{
Sari Ani \\ Universitas Islam Darul Ulum Lamongan \\ Telp. 085755557478 \\ bu.sariani@gmail.com
}

\begin{abstract}
This research was conducted with the aim of describing the functions of legend of lake sarangan stories in Sarangan Village, Kec. Plaosan Kab. East Java Magetan. This research includes qualitative research based on naturalistic approaches. The research data is based on the results of interviews with informants. Data is collected by observation, recording, interviewing and recording methods. Data analysis was carried out in five stages, namely (1) transcribing oral data in written form, (2) summarizing and translating, (3) interpreting. Analysis of the data used in this study is content analysis techniques (conten analysis). The content analysis technique is used in analyzing the function of folklore in the Sarangan lake. The results of the study show that there are functions that include (1) entertainment, (2) institutions of cultural institutions, (3) education, (4) social order, (5) group solidarity, (6) social criticism, (7) pleasant divorce from reality, and (8) potential weapons in society.
\end{abstract}

Keywords: legend of lake sarangan, function

\begin{abstract}
Abstrak: Penelitian ini dilaksanakan dengan tujuan untuk mendeskripsikan fungsi cerita rakyar Telaga Sarangan di Kelurahan Sarangan, Kec. Plaosan Kab. Magetan Jawa Timur. Penelitian ini termasuk penelitian kualitatif yang didasarkan pada pendekatan naturalistik. Data penelitian ini bersumber pada hasil wawancara dengan para informan. Data dikumpulkan dengan metode pengamatan, pencatatan, wawancara dan perekaman. Analisis data dilakukan dalam lima tahapan yakni (1) mentranskrip data lisan dalam bentuk tulis, (2) meringkas dan menerjemahkan, serta (3) menginterpretasikan. Analisis data yang digunakan dalam penelitian ini adalah teknik analisis isi (conten analysis). Teknik analisis isi digunakan dalam menganalisis fungsi cerita rakyat telaga sarangan. Hasil penelitian menunjukan adanya fungsi yang meliputi (1) hiburan, (2) pranata lembaga kebudayaan, (3) pendidikan, (4) tatanan masyarakat, (5) solidaritas kelompok, (6) kritik sosial, (7) peleraian menyenangkan dari kenyataan, dan (8) senjata potensial dalam masyarakat.
\end{abstract}

Kata kunci: Legenda telaga sarangan, fungsi

\section{PENDAHULUAN}

Cerita rakyat merupakan buah pikiran warisan leluhur bangsa mengandung bermacam-macam pesan. Cerita rakyat sebagai bagian dari kebudayaan mengandung berbagai gagasan dan penuh (nilai) makna yang bermanfaat bagi pembangunan bangsa. Cerita rakyat Telaga Sarangan sebagai bagian kebudayaan daerah Sarangan sangat beragam jenis dan isinya. Isinya menunjukan kekayaan rohani dalam bentuk-bentuk nilai-nilai 
moral, gagasan, cita-cita dan pedoman hidup masyarakat Sarangan pada masa lampau baik tentang manusia sebagai pribadi maupun manusia dalam hubungannya dengan alam dan lingkungan hidupnya. Jadi bagaimana para leluhur daerah Sarangan di Kabupaten Magetan dahulu memperlakukan lingkungan hidupnya dapat terproyeksikan dalam cerita rakyat.

Sastra lisan setiap daerah di Indonesia memiliki perbedaan antara daerah yang satu dengan daerah yang lain. Bentuk sastra lisan beraneka ragam meliputi nyanyian rakyat, bahasa rakyat, puisi rakyat, cerita rakyat, dan sebagainya. Cerita rakyat merupakan cerita dari zaman dahulu yang hidup di kalangan rakyat yang diwariskan secara lisan dan bersifat tradisional. Danandjaja (1984:50) mengungkapkan bahwa istilah cerita rakyat merujuk kepada cerita yang merupakan bagian dari rakyat yaitu hasil sastra yang termasuk ke dalam cakupan folkloor.

Danandjaja (1994: 1), kata folklore merupakan kata majemuk yang terdiri atas dua kata yaitu kata folk dan kata lore. Folk mempunyai makna kolektif. Folk adalah sekelompok orang yang memiliki ciri-ciri pengenal fisik, sosial, budaya sehingga dapat dibedakan dari kelompokkelompok lainnya. Sedangkan Danandjaja (1994: 2) menjelaskan lore merupakan tradisi dari folk yaitu sebagian kebudayaannya yang diwariskan secara turun temurun secara lisan atau melalui suatu contoh yang disertai dengan gerak isyarat atau alat pembantu pengingat (mnemonic device). Jadi yang dimaksud folklore adalah sebagian kebudayaan suatu kolektif yang tersebar dan diwariskan turun temurun, di antara kolektif macam apa saja, secara tradisional dalam versi yang berbeda baik dalam bentuk lisan maupun contoh yang disertai dengan gerak isyarat atau alat pembantu pengingat (mnemonic device).
Adapun pengenal ciri utama folklor adalah (a) penyebaran dan pewarisannya biasanya dilakukan secara lisan, ${ }^{1}$ yakni disebarkan melalui tutur kata dari mulut ke mulut (atau dengan contoh yang disertai gerak isyarat, dan alat pembantu pengingat) dari satu generasi ke generasi berikutnya; (b) folklor bersifat tradisional yang disebarkan dalam bentuk relatif tetap atau dalam bentuk yang standar; (c) folklor ada (exist) dalam versi-versi bahkan varian-varian yang berbeda; (d) folklor bersifat anonim yaitu nama penciptanya sudah tidak diketahui lagi; (e) folklor biasanya mempunyai bentuk berumus atau berpola; (f) folklor mempunyai kegunaan (function) dalam kehidupan bersama suatu kolektif; (g) folklor bersifat pralogis yaitu memiliki logika tersendiri yang tidak sesuai dengan logika umum; (h) folklor menjadi milik bersama (collective) dari kolektif tertentu; dan (i) folklor pada umumnya bersifat polos dan lugu, sehingga seringkali kelihatan kasar, terlalu spontan (Danandjaja, 1994: 3-5).

Sehubungan dengan hal itu, dalam penelitian ini penulis mengolaborasikan beberapa teori yang dikemukakan oleh para ahli folklor dalam menganalisis fungsi legenda telaga Sarangan, bahwa objek kajian penulis diasumsikan akan ditemukan beberapa fungsi yaitu: (1) sebagai bentuk hiburan (as form of amusement), dan mengubah pekerjaan yang membosankan menjadi permainan, (2) sebagai alat pengesahan paranatapranata lembaga-lembaga kebudayaan (it plays in validating culture, in justifying its rituals and institution to those who perform an observe them), (3) sebagai alat pendidikan (it plays in education), (4) sebagai alat pemaksa dan pengawas agar norma-norma masyarakat akan

\footnotetext{
${ }^{1}$ Kini penyebaran Folklor dapat terjadi dengan bantuan mesin cetak dan elektronik
} 
selalu dipatuhi anggota kolektifnya (maintaining confirmity to the accepted patterns of behavior, as means of apllying social pressure and exercising social control), dan memberi sangsi sosial agar berperilaku baik atau memberi hukuman, (5) meningkatkan perasaan solidaritas suatu kelompok, (6) sebagai sarana kritik sosial, (7) memberikan suatu pelarian yang menyenangkan dari kenyataan, dan (8) sebagai senjata potensial di dalam memperjuangkan kelas sosial.

\section{METODE PENELITIAN}

Penelitian ini dirancang dalam bentuk penelitian kualitatif yang menggunakan latar alamiah dengan maksud menafsirkan fenomena yang terjadi dan dilakukan dengan jalan melibatkan berbagai metode yang ada. Data utama dalam penelitian ini berupa rangkaian data wawancara dari para informan, narasumber dan sesepuh adat telaga sarangan Kelurahan Sarangan Kec. Palosan Kab. Magetan.

Data fungsi bersumber dari hasil identifikasi dan penemuan data. Selanjutnya, hasil identifikasi data fungsi dikonsultasikan dengan hasil pengamatan terhadap legenda telaga sarangan dan hasil wawancara dengan para informan serta sesepuh adat telaga sarangan. Interpretasi fungsi dalam legenda telaga sarangan dibahas dalam konteks budaya Sarangan .

Jenis data yang dikumpulkan dikonsentrasikan pada fungsi. Sumber data dalam penelitian ini adalah hasil identifikasi data wawancara. Teknik penentuan informan dalam penelitian ini adalah informan kunci dan informan biasa. Informan kunci dalam penelitian ini adalah mbah Supar Sastro Diharjo $\left(75^{\text {th }}\right)$, selaku sesepuh adat telaga sarangan sedangkan tiga informan lainnya yakni Bapak Sukerno (55th), Bapak Munaji (58th) dan Bapak Suwandi (55th) adalah informan biasa, mereka adalah masyarakat pendukung dan penikmat sastra lisan yang peranannya tetap urgen.

Untuk mengumpulkan data dalam penelitian ini digunakan teknik pengamatan, pencatatan, wawancara mendalam dan perekaman. Teknik pengamatan digunakan untuk, (1) mendapatkan data yang didasarkan atas pengalaman secara langsung, (2) melihat dan mengamati sendiri, serta mencatat perilaku dan kejadian sebagaimana yang terjadi pada keadaan. Teknik pencatatan digunakan untuk, (1) mencatat apa saja yang dikehendaki (misalnya langkahlangkah peristiwa, catatan gambaran umum yang singkat), (2) mengumpulkan data dengan jalan mulai menyusun kategori-kategori. Teknik wawancara digunakan untuk menemukan data akurat yang belum ditemukan pada saat pencatatan. Data-data akurat tersebut dapat dijadikan sebagai acuan untuk menganalisis objek kajian penelitian yang sesuai dengan fokus penelitian. Teknik perekaman digunakan untuk merekam data-data yang bersifat natural dengan pendekatan etnografi karena penulis menginginkan konteks asli yang sesuai dengan budaya di mana sastra lisan itu dilesatrikan.

Dalam kegiatan analisis data penelitian ini dilakukan beberapa tahap berikut: (1) mentranskrip data lisan ke dalam bentuk tulis, (2) meringkas, memparafrasekan, dan menerjemahkan ke dalam bahasa laporan, (3) dipahami dan diinterpretasikan, (5) menganalisis data sesuai fungsi legenda telaga Sarangan, (6) merumuskan simpulan hasil penelitian.

\section{HASIL PENELITIAN DAN PEMBAHASAN}

\section{Fungsi Legenda Telaga Sarangan}

Legenda Telaga Sarangan juga memiliki fungsi yang sangat penting 
dalam urusan manusia untuk menafsirkan dan merekonstruksikan realitas dalam menciptakan tatanan-tatanan yang bersifat intelektual dalam kehidupan bermasyarakat. Pembahasan fungsi dalam legenda Telaga Sarangan diklasifikasikan menjadi delapan bagian yakni (1) hiburan, (2) pranata-pranata lembaga kebudayaan, (3) pendidikan, (4) tatanan masyarakat, (5) solidaritas kelompok, (6) kritik sosial (control sosial), (7) peleraian yang menyenangkan dari kenyataan, dan (8) senjata potensial dalam masyarakat.

\section{Hiburan}

Fungsi bentuk hiburan (as form of amusement) dalam hal ini merujuk pada konsepsi mengubah pekerjaan yang membosankan menjadi hal yang menyenangkan. Hal tersebut dapat dicermati dalam legenda telaga sarangan yang berfungsi sebagai cerita hiburan dan pelipur lara ketika berduka. Dengan menghadirkan cerita legenda telaga Sarangan sebagai bentuk hiburan mampu memberi nuansa yang menarik yang memiliki pesan-pesan moral dalam kehidupan sehari-hari.

\section{Pranata-Pranata}

\section{Kebudayaan}

Lembaga

Perilaku tersebut ditampilkan melalui arak-arakan labuh sesaji yang menggambarkan masyarakat Jawa tempo dulu. Dengan demikian, pranata tersebut berfungsi sebagai media visualisasi kepada generasi muda agar menghargai adat budaya dalam wilayahnya.

\section{Pendidikan}

Melalui cerita tersebut masyarakat Sarangan mendidik putra putrinya jangan sampai bersikap ceroboh dan mengambil serta ingin memiliki barang orang lain tanpa izin pemiliknya. Dengan demikian, fungsi legenda telaga sarangan mengandung nilai-nilai edukatif yang mengungkapkan nasihat kepada anakanak Jawa agar tidak bersikap ceroboh dalam mengambil barang orang lain tanpa seizin pemiliknya. Apabila mereka mempunyai sifat demikian maka Allah swt akan memberi ganjaran yang sesuai dengan perbuatannya, jika bukan di dunia ini tentu di dunia sana atau pada penitisan yang akan datang.

\section{Tatanan Masyarakat}

Berkaitan dengan hal ini, dapat dicermati kembali larangan adat yakni dilarang memakai pakaian hijau sutera apabila berkunjung ke telaga sarangan yang dikhawatirkan menyaingi Kusuma Dewi Werdiningsih. Apabila melanggar maka akan hilang raga dan jiwanya serta terjadi hujan deras yang disertai angin puting beliung. Fungsi tatanan masyarakat dalam konteks ini adalah mengajak siapa saja (masyarakat Sarangan atau pengunjung) untuk menegakkan dan mematuhi hukum adat yang berlaku apabila berkunjung ke telaga Sarangan.

\section{Solidaritas Kelompok}

Pandangan cerminan perasaan solidaritas masyarakat ini mengacu pada kegiatan upacara labuh sesaji yang harus dilakukan secara kolektif. Solidaritas tersebut tampak dari semua pihak baik masyarakat Sarangan, Pemerintah Karisedenan Madiun maupun pemerintah kabupaten Magetan, serta wisatawan lokal maupun interlokal. Semuanya berpartisipasi mengikuti acara labuh sesaji. Dengan demikian, fungsi labuh sesaji sebagai pengikat solidaritas masyarakat Sarangan di manapun mereka berada. Dalam kondisi seperti ini stratifikasi sosial bukan lagi hal yang ditonjolkan, tetapi kegiatan ini merupakan kesempatan yang baik untuk memupuk semangat persatuan dan kesatuan dengan semangat jiwa gotong royong dan rasa kebersamaan.

\section{Kritik Sosial (Control Sosial)}

Fungsi legenda telaga sarangan sebagai kritik sosial merujuk pada konsepsi sarana kritik sosial dan kendali masyarakat (control sosial) atau protes sosial terhadap norma-norma adat yang 
berlaku di Sarangan. Fungsi ini dapat dicermati pada kebijakan pemerintah yang adigang, adigung, adiguna di wilayah Sarangan seperti yang terjadi dalam kegiatan pembangunan irigasi atau perbaikan jalan. Pemerintah setempat kurang memperhatikan, sehingga warga masyarakat memutuskan untuk melakukan gotong royong mandiri. Gotong royong merupakan budaya bangsa yang telah lama. Diharapkan gotong royong menjadi landasan semangat untuk membangun bangsa. Dengan gotong royong dapat memupuk rasa persatuan dan kesatuan untuk bersatu maju membangun bangsa. Hal ini sesuai dengan intisari dari Pancasila yakni gotong royong dengan tujuan untuk mencapai keadilan sosial bagi seluruh rakyat Indonesia. Dengan demikian, cerita legenda telaga sarangan tersebut sebagai media kritik sosial yang berupa tanggapan atas nilai-nilai kesusilaan yang berkembang dalam masyarakat agar mengubah tatanan yang salah melalui pembenahan sikap intelektual. Fungsi ini menjabarkan bahwa pemerintah adalah orang yang terhormat, jangan memiliki sikap adigang, adigung, adiguna karena akan membawa kehancuran bagi dirinya sendiri maupun orang lain.

\section{Peleraian yang Menyenangkan dari Kenyataan}

Fungsi legenda Telaga Sarangan sebagai suatu peleraian yang menyenangkan dari kenyataan mengarah pada tanggapan masyarakat baik yang berkunjung atau yang berada di wilayah Sarangan sendiri yang berpendapat bahwa Telaga Sarangan sering digunakan sebagai tempat ngalap berkah, seperti melakukan ritual pesugihan dengan cara memberi persembahan kepala kambing, dan sebagainya. Berdasarkan cerita yang beredar di masyarakat, setiap hari Jumat Legi bagi masyarakat yang berkeinginan ngalap berkah mereka membakar menyan serta meletakan sesaji persembahan, di bawah pohon bolu yang terletak di sebelah timur hotel Kintamani. Konon pohon tersebut merupakan pusat persembahan untuk mencari pesugihan dan sebagai pintu gerbang ${ }^{2}$ memasuki alam lain. Selain itu, Telaga Sarangan juga digunakan sebagai tempat nadzar atau syukuran jika keinginannya terkabul yakni sebagai wujud rasa syukur misalnya terbebas dari hutang, sembuh dari penyakit, dan sebagainya. Banyak masyarakat yang melaksanakan nadzar (janji) tersebut. Janji adalah hutang, siapa memiliki janji berarti hutang dan hutang harus dibayar. Dengan demikian, oarang yang ingkar atau tidak menepati janji harus sanggup menanggung hukuman sebagai akibat pelanggaran norma-norma adat yang berlaku. Melalui fungsi ini diharapkan agar setiap masyarakat menepati janji yang dibuat atau disepakati. Bentuk nadzarnya pun bermacam-macam seperti melaksanakan acara slamaten berupa tumpeng kecil kemudian dilarungkan ke telaga Sarangan atau hanya sekadar slametan dengan mengundang beberapa warga masyarakat Sarangan yang kemudian doanya langsung dipimpin Mbah Supar Sastro Diharjo (sebut: juru kunci).

\section{Senjata Potensial dalam Masyarakat}

Fungsi legenda Telaga Sarangan sebagai senjata potensial di dalam memperjuangkan kelas sosial bersumber pada upacara labuh sesaji. Hal ini terlihat dari upacara labuh sesaji yang diadakan setiap tahun oleh masyarakat Sarangan pada hari Jumat Pon, bulan Muharam (Bahasa Jawa: suro). Upacara tersebut menggambarkan bahwa fungsi legenda Telaga Sarangan sudah mendarah daging

\footnotetext{
${ }^{2}$ Pohon bolu tersebut merupakan tempat tinggal Kyai Pasir dan Nyai Pasir (hasil wawancara dengan informan Bapak Suwandi/ tukang sewa kuda tanggal 14 Mei 2011)
} 
yakni sebagai senjata potensial untuk tidak menghilangkan upacara labuh sesaji. Kegiatan tersebut banyak mengandung makna hidup karena sejak dulu para nenek moyang dan leluhur, dalam menyampaikan petuah dan ajaran tentang hidup ini tidaklah ditulis pada selembar kertas melainkan menggunakan apa yang ada di alam ini sebagai sarananya. Bagi ajaran Jawa, alam ini (jagad kang gumelar) merupakan ayatayat kehidupan. Begitu pula, dalam kegiatan labuh sesaji semua sesaji persembahan juga mengandung makna yang sangat dalam yang memiliki konsepsi pandangan hidup yang luhur.

Hal ini sesuai dengan teori fungsi ala William R. Bascom bahwa beberapa fungsi foklor bersifat umum, yaitu (1) hiburan, (2) pranata-pranata lembaga kebudayaan, (3) pendidikan, (4) tatanan masyarakat, (5) solidaritas kelompok, (6) kritik sosial (control sosial), (7) peleraian yang menyenangkan dari kenyataan, dan (8) senjata potensial dalam masyarakat.

\section{SIMPULAN}

Penelitian legenda Telaga Sarangan ini merupakan penelitian sastra lisan yang prosedurnya berpedoman pada pendekatan naturalistik. Dengan pendekatan naturalistik, penelitian ini dapat disimpulkan dalam beberapa fungsi bagi masyarakat pendukungnya yang merujuk sebagai berikut (1) hiburan, (2) pranata-pranata lembaga kebudayaan, (3) pendidikan, (4) tatanan masyarakat, (5) solidaritas kelompok, (6) kritik sosial (7) peleraian menyenangkan dari kenyataan, dan (8) senjata potensial dalam masyarakat.

Selanjutnya, hasil penelitian ini memiliki implikasi praktis dalam pengembangan bidang, misalnya dalam bidang pendidikan. Implikasi dalam bidang pendidikan, hasil penelitian dapat dipergunakan sebagai bahan rujukan dan kajian untuk menyusun bahan pembelajaran oleh guru bidang studi Bahasa dan Sastra Indonesia baik di SMP maupun SMA khususnya kompetensi dasar yang ada hubungannya dengan cerita rakyat nusantara. Selain itu, hasil penelitian tersebut juga dapat dimanfaatkan orang tua dalam mendidik dan mengajarkan nilai-nilai moral pada anak-anaknya melalui cerita rakyat telaga sarangan.

\section{DAFTAR RUJUKAN}

Danandjaya, James. 1994. Fokloor Indonesia: Ilmu Gosip, Dongeng. Jakarta. Grafiti Pres.

Metodologi Penelitian Folklor: Konsep, Teori dan Aplikasi. Yogyakarta: Medpress.

2003.

Metodologi Penelitian Sastra: Epistimologi, Model, Teori dan Aplikasi. Yogyakarta: Pustaka Widiatama.

Hutomo, Suripan Sadi. 1991. Mutiara yang Terlupakan: Pengantar Studi Sastra Lisan. Surabaya: HISKI Komisariat JATIM.

Moleong, Lexy. 2009. Metodologi Penelitian Kualitatif. Bandung: PT. Remaja Rosda Karya.

Muhadjir, Noeng. 1996. Metodologi Penelitian Kualitatif. Yogyakarta: Rake Sarasin.

Mulyasa, E. 2006. Kurikulum Tingkat Satuan Pendidikan. Bandung: PT. Remaja Rosda Karya.

Poerwadarminta, W.J.S. 1985. Kamus Besar Bahasa Indonesia. Jakarta: Balai Pustaka.

Sudikan, Setya Yuwana. 2015. Metode Penelitian Sastra Lisan. Surabaya: Citra Wacana. 